\title{
Measuring the Patients' Satisfaction About Telemedicine Used in Saudi Arabia During COVID-19 Pandemic
}

Asmaa Abdel Nasser ${ }^{1,2}$, Razan Mohammed Alzahrani ${ }^{3}$, Chaimaa Aziz Fellah ${ }^{3}$, Dimah Muwafak Jreash ${ }^{3}$, Norah Talea A Almuwallad ${ }^{3}$, Dunya Salem A Bakulka ${ }^{3}$, Rabab Abdel Ra'oof Abed ${ }^{1}$

1. Medical Education Department, Faculty of Medicine, Suez Canal University, Ismailia, EGY 2. Medical Education Unit, Ibn Sina National College for Medical Studies, Jeddah, SAU 3. Medical Student, Ibn Sina National College for Medical Studies, Jeddah, SAU

Corresponding author: Asmaa Abdel Nasser, dr.asmaashraf@gmail.com

\section{Abstract \\ Background}

Many studies have found that telemedicine and telehealth services quality and patients' clinical outcomes, following telehealth visits, maybe comparable to those of traditional face-to-face office visits especially in a crisis like COVID-19 complete lockdown.

\section{Objective}

This study aimed to identify the patient's experience in using the telemedicine strategies during the COVID19 pandemic and assess these patients' perception about their experience of using telemedicine in Saudi Arabia.

\section{Methods}

A cross-sectional survey study was done on 425 patients treated through telemedicine programs in Saudi Arabia from February to August 2020 during the COVID-19 pandemic in Saudi Arabia. An online questionnaire was adopted and modified to elicit participants' socio-demographic data, participants' satisfaction and attitude toward telehealth and telemedicine, and their views on health care services.

\section{Results}

About $84.9 \%$ of the participants thought that telemedicine made healthcare easier during the COVID-19 pandemic. Almost half of the respondent was very satisfied with the ease of registration (52\%), while $43.4 \%$ of respondents stated that they had the ability to talk freely over telemedicine. In the present study, The highest satisfaction was reported by $53.4 \%$ of respondents for ease registration, $40.1 \%$ for quality of the visual image, $41.9 \%$ for quality of the audio sound, and $44.8 \%$ for their ability to talk freely over telemedicine, respectively. The highest satisfaction was reported by $40.5 \%$ about the ability to understand the recommendations, $40.5 \%$ about the overall quality of care provided, $37.4 \%$ about the overall telemedicine consult experience. The results revealed a significant positive correlation between satisfaction and attitude scores.

\section{Conclusion}

This study revealed acceptable satisfaction and attitude of patients toward telemedicine programs in Saudi Arabia. However, more effort should be done by the Saudi Ministry of Health to increase the knowledge of patients about teleconsultation available services.

Categories: Internal Medicine, Medical Education, Healthcare Technology

Keywords: telemedicine, patients' satisfaction, covid-19, telehealth

\section{Introduction}

In response to expanding technological developments in the world, healthcare systems require a paradigm shift in the way health services are delivered like telemedicine which supports using of electronic information and advanced telecommunication technologies to support long-distance clinical healthcare [1]. Telemedicine was defined by the World Health Organization as "the delivery of health care services by all health care professionals using technology for the exchange of valid information for the diagnosis, treatment, and prevention of disease and injuries" [2].

As coronavirus disease (COVID-19) is widely spreading across the Kingdom of Saudi Arabia (KSA) from the start of March 2020, patients have a fear that they will get infected when they go to hospitals to receive 
treatment, medical advice, and follow-up. Responding to that the patients expect to have diverse technologies that enable them to continue living in their house and be more informed and engaged in their own health and minimizing exposure to healthcare facilities [3].

Several studies have found that the quality of telehealth services and patients' clinical outcomes following telehealth visits may be comparable to those of traditional face-to-face office visits, with the additional benefit of fast access to care [4], and a recent meta-analysis has found that teleconsultation provided a rapid alternative to face-to-face clinical visits [5]. It was also found to be an effective triage method to evaluate patients' complaints, prevent unnecessary clinical visits, and reduce the waiting time [6].

During the pandemic, telemedicine was found effective in screening patients who may have symptoms of COVID-19. In addition, it was an appropriate method to provide low-risk urgent care for non-COVID-19 conditions, monitor clinical signs of certain chronic medical conditions, and follow up of patients after hospitalization [7]. A lot of countries implemented teleconsultation during the COVID-19 pandemic [8-11]. However, it is not currently known whether this available service has satisfied the patients' needs during the COVID-19 pandemic so for [12].

In June 2019, new regulations on telemedicine were published in the Kingdom of Saudi Arabia (KSA), providing a comprehensive framework for all clinical staff, which is overseen by the Saudi Telemedicine Unit of Excellence (STUE) as part of the National Health Information Centre. The publication of these regulations provides a foundation to rapidly implement video consultations across the Kingdom, hence, the use of telemedicine began to increase [13]. A recent study was done in Riyadh to measure satisfaction toward a tele-retinal screening program among diabetics attending endocrinology clinics at a tertiary hospital. The study found that patients were found to be highly satisfied with the tele-retinal screening program. At the same time, there is a reason for dissatisfaction which was the difficult accessibility to an ophthalmologist when a referral was needed [14].

According to a careful literature review, there is no published study from KSA assessing patients' satisfaction with telemedicine during COVID-19. The aim of the present study was to assess the patients' satisfaction with their experience of using telemedicine strategies under the COVID-19 pandemic.

\section{Materials And Methods}

\section{Study type and setting}

A cross-sectional survey study was done among patients who were treated from February to August 2020 through telemedicine programs all over Saudi Arabia.

\section{Study participants and sampling methodology}

The study was done on 425 patients who were treated through telemedicine programs in Saudi Arabia. Patients who were 18 years of age or older and who participated in telehealth visits or follow up (out-patient clinics in different specialties) during COVID-19 were included. The estimated online sample size by the equation for $50 \%$ prevalence of patients who used telemedicine during COVID-19 pandemics in Saudi Arabia revealed that our target sample should be 383 participants or more to have a confidence level of $95 \%$ that the real value is within $\pm 5 \%$. Participants were selected consequently using non-randomized voluntary response sampling [15].

\section{Study instrument}

Data were collected by an online questionnaire that was disseminated through various social media platforms to reach wide sectors of the Saudi community, which was adopted and modified to elicit participants' socio-demographic data, participants' satisfaction, and attitude toward telehealth and telemedicine, their views on healthcare services in Saudi Arabia during COVID-19 pandemic. The satisfaction of the participants was assessed by newly developed eight questions on a Likert scale that has five options. Each option was given a score that ranged from 1, which was given to the "strongly disagree" response, to 5 that was given to the "strongly agree" score. So, the satisfaction scores ranged from 8 to 40 . The attitude of the participants towards telemedicine was detected by using five questions checklist with two responses; "yes" that was given a 2 score and "no" that was given a 1 score. So, the attitude score ranged from 5 to 10 .

\section{Ethical considerations}

The Ethical clearance for the study was obtained from the Ibn Sina National College Research and Ethics committee (IEC Ref No.: H-24-19102020). All the participants were informed about the purpose of the study and their right to refuse participation. Ethical conduct was maintained during data collection and throughout the research process in accordance with the Helsinki Declaration [16]. Participation in the study was voluntary and the confidentiality of the participants was maintained as the questionnaire was provided anonymously. Each participant had the right to withdraw from the study at any point without any consequences. 


\section{Cureus}

\section{Statistical analysis}

Data analyzed by SPSS program version 23, where quantitative data was expressed as numbers and frequencies. Also, we used mean and standard deviation (mean \pm SD) to measure the average and spread of participants' responses and for non-parametric variables. Mann-Whitney, Kruskal Wallis tests, and Spearman's correlation analysis were used. A p-value $<0.05$ was used as a cutoff point for statistical significance.

\section{Results}

The collected responses were 425 who were treated through telemedicine programs in Saudi Arabia. Table 1 shows that $36.9 \%$ of the study participants had an age that ranged from 18 to 25 years, $63.1 \%$ were females, and $76.6 \%$ had a Saudi nationality.

\begin{tabular}{|c|c|c|}
\hline \multicolumn{2}{|l|}{ Variable } & No (\%) \\
\hline \multirow{4}{*}{ Age } & $18-25$ & 157 (36.9) \\
\hline & $26-35$ & $85(20)$ \\
\hline & $36-45$ & $112(24.5)$ \\
\hline & 45 & 71 (16.7) \\
\hline \multirow{2}{*}{ Gender } & Female & $268(63.1)$ \\
\hline & Male & 157 (36.9) \\
\hline \multirow{2}{*}{ Nationality } & Saudi & 326 (76.6) \\
\hline & Non-Saudi & $99(23.3)$ \\
\hline
\end{tabular}

TABLE 1: Distribution of the Studied Participants According to Their Characters and Being a Patient on the Telemedicine Network Before $(n=425)$

Table 2 illustrates that most of the participants agreed that they think telehealth services made healthcare easier today during the COVID-19 pandemics. Furthermore, the majority of them thought that in case you need healthcare, they might have to miss work/get things done to see a therapist if telehealth services are not available. On the other hand, less than half of the participants will prefer telemedicine consultation in the future, and $80.2 \%$ of them thought that the presence of the camera and other equipment can embarrass them and make them feel uncomfortable. Table 3 shows that most of the participants responses ranged between very satisfied and satisfied especially for ease of registration/ scheduling (52\%), quality of the visual image (38.8\%), quality of audio, the ability to understand the recommendations or diagnosis made, and the comfort of telemedicine suite (40.5\%), and ability to talk freely over telemedicine $(43.5 \%) / 37.4 \%$ and $36.7 \%$ were very satisfied with the overall quality of care provided, and the overall telemedicine consults experience, respectively. 


\section{Cureus}

\begin{tabular}{|c|c|c|c|c|c|}
\hline \multirow[b]{2}{*}{ Variable } & \multicolumn{5}{|l|}{ Response } \\
\hline & $\begin{array}{l}\text { Very satisfied } \\
\text { (\%) }\end{array}$ & $\begin{array}{l}\text { Satisfied } \\
\text { (\%) }\end{array}$ & $\begin{array}{l}\text { Neutral } \\
(\%)\end{array}$ & $\begin{array}{l}\text { Dissatisfied } \\
\text { (\%) }\end{array}$ & $\begin{array}{l}\text { Very dissatisfied } \\
(\%)\end{array}$ \\
\hline Ease of registration/scheduling & $221(52)$ & $135(31.8)$ & $56(13.2)$ & $12(2.8)$ & $1(0.2)$ \\
\hline Quality of the visual image & $165(38.8)$ & $167(39.3)$ & $73(17.2)$ & $18(4.2)$ & $2(0.5)$ \\
\hline Quality of the audio sound & $172(40.5)$ & $160(37.6)$ & 78 (18.4) & $12(2.8)$ & $3(0.7)$ \\
\hline Ability to talk freely over telemedicine & $185(43.5)$ & $158(37.2)$ & 69 (16.2) & $12(2.8)$ & $1(0.2)$ \\
\hline $\begin{array}{l}\text { Ability to understand the recommendations or diagnosis } \\
\text { made }\end{array}$ & $72(40.5)$ & $169(39.8)$ & $61(14.4)$ & $21(4.9)$ & $2(0.5)$ \\
\hline $\begin{array}{l}\text { The comfort of the telemedicine suite (the location where I } \\
\text { received my care) }\end{array}$ & $172(40.5)$ & $160(37.6)$ & 74 (17.4) & $18(4.2)$ & $1(0.2)$ \\
\hline The overall quality of care provided & $159(37.4)$ & $59(37.4)$ & $80(18.8)$ & $25(5.9)$ & $2(0.5)$ \\
\hline Overall telemedicine consult experience & $156(36.7)$ & $175(41.2)$ & $79(18.6)$ & $14(3.3)$ & $1(0.2)$ \\
\hline
\end{tabular}

TABLE 2: Distribution of the Studied Participants According to Their Response to Satisfaction Items Regarding Telemedicine $(n=425)$

Variable

Do you think telehealth services made healthcare easier today during the virus COVID-19 pandemic?

In case you need healthcare, do you think you might have to miss work/get things done to see a

$$
\text { Agree }
$$

therapist if telehealth services are not available?

$\begin{array}{ll}\text { I do not agree } & 64 \\ \text { Agree } & (15.1) \\ & 344 \\ & (80.9) \\ \text { I do not agree } & 81 \\ & (19.1) \\ \text { Telemedicine } & 208 \\ \text { consultation } & (48.9) \\ \text { Face-to-face } & 217 \\ \text { consultation } & (51.1) \\ & 171 \\ \text { Yes } & (40.2) \\ & 254 \\ \text { No or not sure } & (59.8) \\ & 341 \\ \text { Agree } & (80.2) \\ & 84 \\ \text { I do not agree } & (19.8) \\ & \\ & \end{array}$

Do you think the presence of the camera and other equipment can embarrass you or make you feel uncomfortable?

Would you be willing to participate in another telemedicine consultation?

TABLE 3: The Participants' Attitude Towards Telemedicine ( $n=425)$

The participants reported that if telemedicine had not been available for their consult today, they would drive to meet the specialist face-to-face (43.5\%), and 34.1\% reported that they would travel for less than 15 minutes to receive care. The participants reported that if telemedicine had not been available and they had to travel to meet face-to-face with the provider, the most affected item would be that their companions 


\section{Cureus}

would have lost time from work (35.5\%). Only $4.2 \%$ of the participants thought that telemedicine is suitable for all medical cases, and they thought that chronic diseases are the most suitable to be cared for by telemedicine (30.4\%; Table 4 and Figure 1$)$.

\begin{tabular}{|c|c|c|}
\hline \multicolumn{2}{|l|}{ Items } & $\begin{array}{l}\text { No } \\
\text { (\%) }\end{array}$ \\
\hline \multirow{4}{*}{$\begin{array}{l}\text { If telemedicine had not been available for your consult today, which of the } \\
\text { following would have been your alternative plan of action? }\end{array}$} & $\begin{array}{l}\text { I would have driven to see the specialist } \\
\text { face-to-face }\end{array}$ & $\begin{array}{l}185 \\
(43.5)\end{array}$ \\
\hline & $\begin{array}{l}\text { I would have contacted my local clinical to } \\
\text { see if they could assist }\end{array}$ & $\begin{array}{l}100 \\
(23.5)\end{array}$ \\
\hline & I would not go see any doctor & $\begin{array}{l}32 \\
(7.5)\end{array}$ \\
\hline & $\begin{array}{l}\text { The use of alternative medicine (honey - } \\
\text { nigella - Indian installment, etc.) } 12,111\end{array}$ & $\begin{array}{l}108 \\
(25.4)\end{array}$ \\
\hline \multirow{5}{*}{$\begin{array}{l}\text { If telemedicine had not been available for your consult today, how far would you } \\
\text { have had to travel to receive care? }\end{array}$} & Less than 15 minutes & $\begin{array}{l}145 \\
(34.1)\end{array}$ \\
\hline & $15-30$ minutes & $\begin{array}{l}139 \\
(32.7)\end{array}$ \\
\hline & 30 minutes to 1 hour & $\begin{array}{l}78 \\
(18.4)\end{array}$ \\
\hline & 1-2 hours & $\begin{array}{l}49 \\
(11.5)\end{array}$ \\
\hline & More than 2 hours & $\begin{array}{l}14 \\
(3.3)\end{array}$ \\
\hline \multirow{4}{*}{$\begin{array}{l}\text { If telemedicine had not been available and you had to travel to meet face-to-face } \\
\text { with the provider to receive care, which of the following would apply? }\end{array}$} & I would have lost time from work & $\begin{array}{l}114 \\
(26.8)\end{array}$ \\
\hline & $\begin{array}{l}\text { My companions would have lost time } \\
\text { from work }\end{array}$ & $\begin{array}{l}151 \\
(35.5)\end{array}$ \\
\hline & $\begin{array}{l}\text { I would have paid for meals while I was } \\
\text { away from home }\end{array}$ & $\begin{array}{l}55 \\
(12.9)\end{array}$ \\
\hline & $\begin{array}{l}\text { I would have paid for a hotel to spend the } \\
\text { night }\end{array}$ & $\begin{array}{l}105 \\
(24.7)\end{array}$ \\
\hline \multirow{2}{*}{ think telemedicine is suitable for all medical } & No & $\begin{array}{l}269 \\
(63.3)\end{array}$ \\
\hline & Yes & $\begin{array}{l}156 \\
(36.7)\end{array}$ \\
\hline
\end{tabular}

TABLE 4: Frequency of the Participants' Responses to Different Items Related to Telemedicine $(n=425)$ 


\section{Cureus}

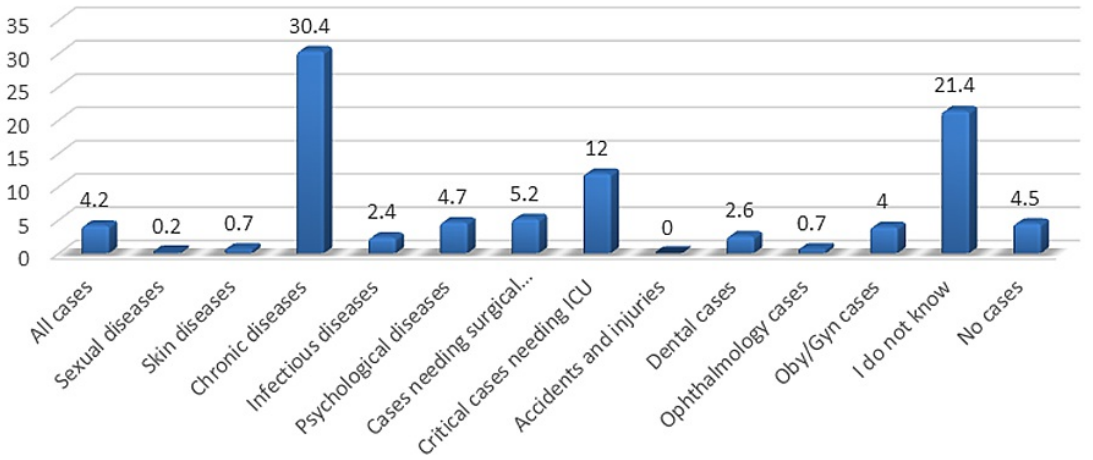

FIGURE 1: Distribution of the Studied Participants' Opinion About the Most Suitable Diseases to be Managed by Telemedicine $(n=425)$

The mean satisfaction and attitude scores were $33.24 \pm 5.94$ and $9.72 \pm 1.24$, respectively. Participants with an age ranging from 18 to 25 years and those of Saudi nationality had a significantly higher mean satisfaction score compared to other participants $(p \leqslant 0.05)$. While a non-significant difference was found between satisfaction scores and participants' gender and being a patient on the telemedicine network before $(\mathrm{p} \geqslant 0.05$; Table 5$)$.

\begin{tabular}{|c|c|c|c|c|}
\hline \multicolumn{2}{|l|}{ Variable } & Satisfaction score (mean \pm SD) & Test & p-Value \\
\hline \multirow{4}{*}{ Age } & $18-25$ & $34.4 \pm 5.74$ & \multirow{4}{*}{$3^{\star *}$} & \multirow{4}{*}{$0.002^{*}$} \\
\hline & $26-35$ & $32.69 \pm 6.31$ & & \\
\hline & $36-45$ & $33.12 \pm 5.91$ & & \\
\hline & $>45$ & $31.52 \pm 5.56$ & & \\
\hline \multirow{2}{*}{ Gender } & Female & $33.5 \pm 6.33$ & \multirow{2}{*}{$1.18^{\star \star \star}$} & \multirow{2}{*}{0.23} \\
\hline & Male & $33.08 \pm 5.71$ & & \\
\hline \multirow{2}{*}{ Nationality } & Saudi & $33.68 \pm 5.77$ & \multirow{2}{*}{$2.64^{\star \star \star}$} & \multirow{2}{*}{$0.008^{*}$} \\
\hline & Non-Saudi & 31.836 .29 & & \\
\hline
\end{tabular}

\section{TABLE 5: Relationship Between Participants' Mean Satisfaction Score and Their Characters} $(n=425)$

*Statistically significant $p$-value $<0.05$.

${ }^{* *}$ Kruskal-Wallis test.

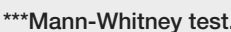

As for participants' attitudes towards telemedicine, female participants had a significantly higher mean attitude score compared to other participants $(\mathrm{p} \leqslant 0.05)$. On the other hand, a non-significant difference was found between satisfaction scores and participants' age and nationality ( $\mathrm{p} \geqslant 0.05$; Table 6$)$. 


\section{Cureus}

\begin{tabular}{|c|c|c|c|c|}
\hline \multicolumn{2}{|l|}{ Variable } & Attitude score (mean $\pm \mathrm{SD}$ ) & Test & p-Value \\
\hline \multirow{4}{*}{ Age } & $18-25$ & $8.2 \pm 1.01$ & \multirow{4}{*}{$3^{\star \star}$} & \multirow{4}{*}{0.17} \\
\hline & $26-35$ & $8.4 \pm 1.04$ & & \\
\hline & $36-45$ & $8.58 \pm 1.02$ & & \\
\hline & $>45$ & $8.19 \pm 1.09$ & & \\
\hline \multirow{2}{*}{ Gender } & Female & $8.4 \pm 1.01$ & \multirow{2}{*}{$3.03^{\star \star \star}$} & \multirow{2}{*}{$0.002^{*}$} \\
\hline & Male & $8.37 \pm 1.06$ & & \\
\hline \multirow{2}{*}{ Nationality } & Saudi & $8.35 \pm 1.03$ & \multirow{2}{*}{$0.64^{\star \star \star}$} & \multirow{2}{*}{0.52} \\
\hline & Non-Saudi & $8.33 \pm 1.09$ & & \\
\hline
\end{tabular}

TABLE 6: Relationship Between Participants' Mean Attitude Score and Their Characters $(n=425)$

*Statistically significant $p$-value $<0.05$.

${ }^{\star *}$ Kruskal-Wallis test.

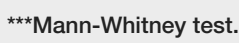

Figure 2 demonstrated a significant positive correlation between satisfaction scores and attitude scores $(\mathrm{r}=0.35, \mathrm{p} \leqslant 0.001)$.

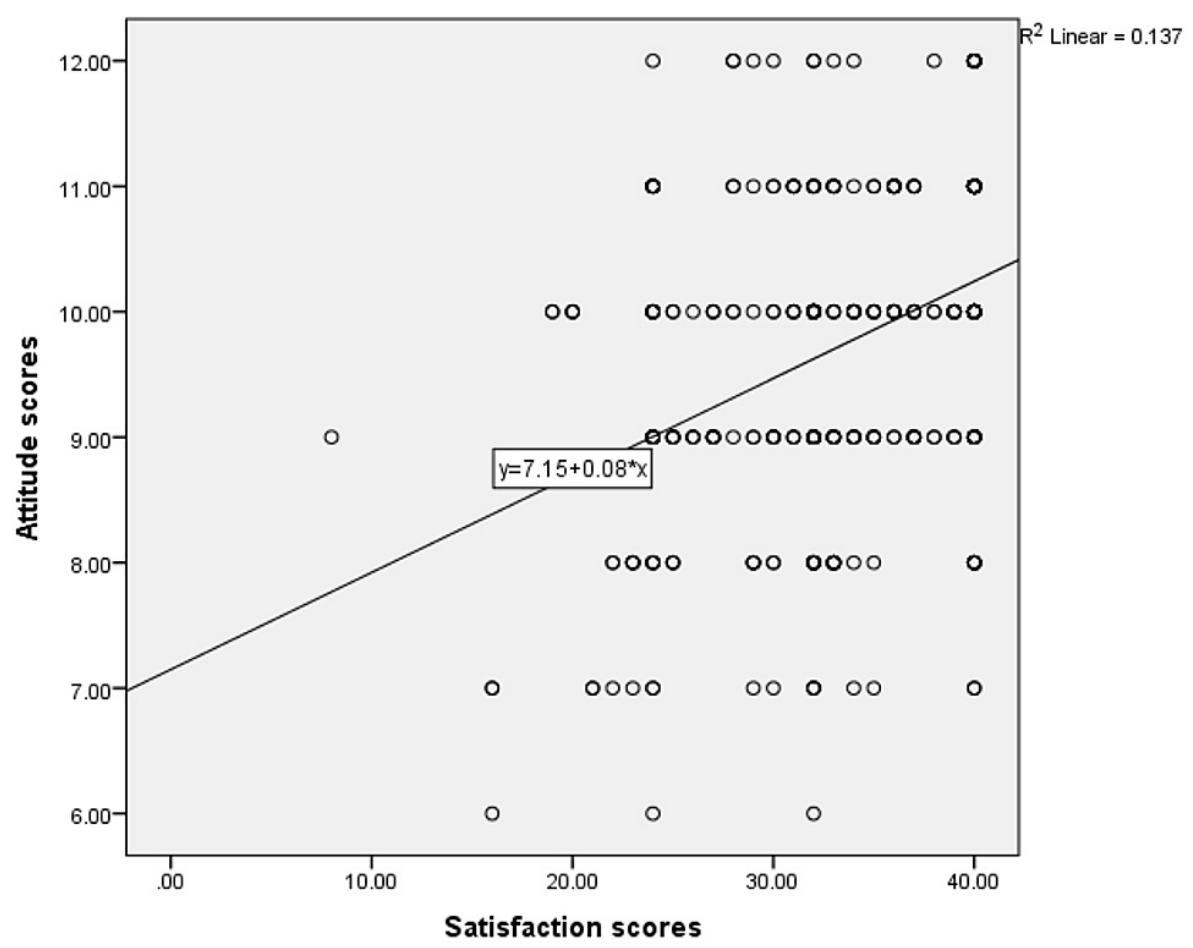

FIGURE 2: Spearman's Correlation Analysis Between Satisfaction and Attitude Scores $(n=425)$

N.B.: $(r=0.35, p \leq 0.001)$.

\section{Discussion}

This research work aims to measure the patients' satisfaction regarding the use of tele-healthcare services 
during the COVID-19 pandemic in KSA. Traditionally, healthcare encounters a relationship between a provider and a patient being in the same place (in person) [16]. Over the past 20 years, the internet and technology have made it possible for healthcare to be delivered digitally, providing new avenues for the medicine to improve the value of care [17]. The strengths of telemedicine have made it an indispensable tool in the clinical response to the COVID-19 pandemic [18]. With the removal of financial disincentives and privacy barriers that limited widespread adoption of telemedicine, the Saudi Vision 2030 framework, released in 2017, has paved the path for technology transformation, the pandemic of COVID-19 enabled the promotion and testing of this transition [19].

Most of the participants realize that telehealth services made healthcare easier today during pandemics or any similar situation. Most of them were very satisfied with the ease of registration/scheduling, quality of the visual image, quality of the audio sound, and ability to talk freely over telemedicine. In this context, telemedicine consultation got around the restrictions of lockdown, making follow-up possible; this may well account for the high rate of satisfaction, but also means the results cannot be extrapolated to telemedicine in general [20].

Prior studies have shown similar high patients' satisfaction with telemedicine (4), and clinical outcomes of patients using telemedicine services were found to be comparable with those using traditional "in-person" clinic visits [21,22]. However, these studies were done in the developed countries where telemedicine is better established than it is in KSA and many other countries around the world [23].

In this study, most of the participants reported that if telemedicine had not been available, and they had to travel to meet with their health care provider face-to-face, their companions would have lost time from work [20]. The participants thought that telemedicine is not suitable for all medical cases, and most of them thought that chronic disease follow-up is the most suitable to be cared for by telemedicine. A systematic review done in 2019 supported our result and showed that to manage COVID-19, there are many easy-toset-up potentials in live video consulting [24]. Studies have found that live video conferencing can lead to the avoiding of direct physical contact, thereby diminishing the risk of exposure to respiratory secretions, and preventing the potential transmission of infection to physicians and other healthcare providers [25]. Also, the live video could be very useful for patients seeking consultation on COVID-19, for people with heightened anxiety, instead of in-person visits in cases of chronic disease reviews (such as diabetes and cancer), some medication checks, and triage when the telephone is insufficient [26].

In this work, the participants were very satisfied with the ability to understand the recommendations or diagnosis made, the comfort of the telemedicine suite, the overall quality of care provided, and the overall telemedicine consult experience, respectively. It was found that to control the COVID-19 outbreak the spread, video consultations, and telephone follow-up is possible in multiple cancer settings [27]. A study done in the USA showed that electronic health records (EHR) and phone calls facilitated screening or treating a patient without the need for in-person visits and improve the decision-making process among healthcare workers in ambulatory and urgent care [28].

Most of the old age participants in our study would prefer to use face-to-face consultation in the future rather than telemedicine; this may be due to their age generation and they need in-person contact to discuss more their emotional issues, and to express all his/her concerns verbally and nonverbally. There was a significant positive correlation between patients' satisfaction and attitude scores toward telemedicine. Many studies highlighted the impact of telehealthcare services during the COVID-19 pandemic for keeping social distancing from high-risk areas, which will prevent morbidity [24].

As for participants' satisfaction and attitude towards telemedicine, participants with an age ranging from 18 to 25 years had a significantly higher mean satisfaction score compared to other participants, this may be for the reason that they are young age with more familiarity with the use of technology. A non-significant difference was found between satisfaction scores and the participants' gender, as the female participants had a significantly higher mean attitude score compared to other participants. Also, a non-significant difference was found between satisfaction scores and participants' age and nationality. In a previous study, predictors of liking telehealth were female gender, being very satisfied with and understanding of telehealth, and quality of care received [4].

The barriers encountered to adopt telehealth services for large-scale use during COVID-19 infection are the adaptation of health systems with rapid changes regarding payment and coordination of services

[29]. Despite showing an overall high satisfaction rate with the telemedicine services in this study, we should take into our consideration the possible response bias that can affect the outcome. In addition, the results of this study cannot be generalized to all medical subspecialties as the applicability of telemedicine consultations in different subspecialties must be determined individually.

\section{Conclusions}

The COVID-19 pandemic is making changes and increasing the need to apply telehealth more firmly. The current study revealed adequate satisfaction and attitude of patients towards telemedicine consultation 


\section{Cureus}

services at the lock down time of COVID-19. However, more effort should be done by the Saudi Ministry of Health (MOH) to increase the patients' awareness and knowledge about teleconsultation services. Future studies assessing physicians' perception toward Telemedicine and teleconsultation options should be encouraged.

\section{Appendices}

If you participated in telehealth consultation services during the COVID-19 pandemic, please specify do you would like to participate in this research?

I want

I do not want

1. Age:

18- 25

$26-35$

$36-45$

$46-55$

2. Sex:

Man

Woman

3. What is Your Nationality?

Saudi

Non-Saudi

4. Is the first time you have been seen as a patient on the telemedicine network?

Yes

No

5. Mention the hospital (center) where you have an appointment for telemedicine?

6. What physician and location were you connecting with?

7. How would you rate your telemedicine consultation on the factors listed below? 


\section{Cureus}

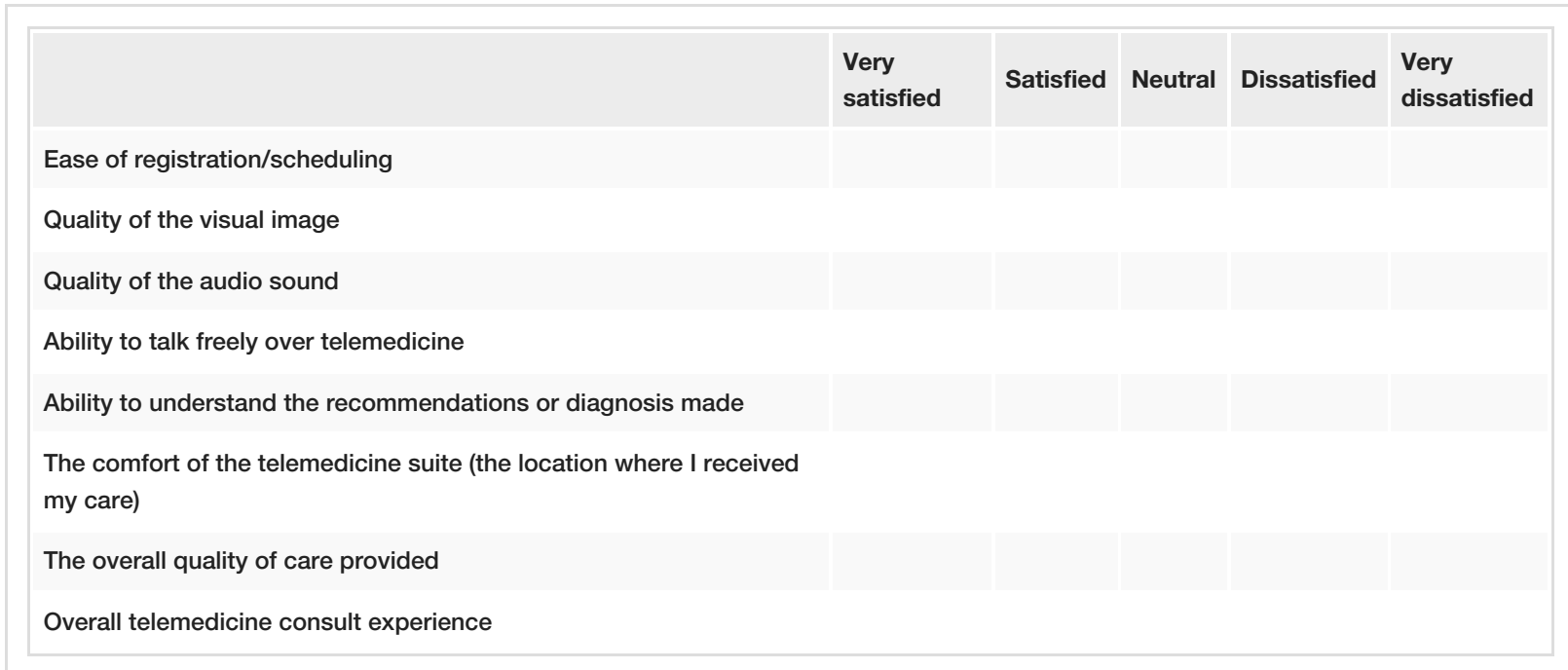

\section{TABLE 7: Factors for Telemedicine Consultation}

8. Do you think telehealth services made healthcare easier today during the virus Covid 19 pandemic?

Agree

I don't agree

9. In case you need healthcare, do you think you might have to miss work/get things done to see a therapist if telehealth services are not available?

Agree

I don't agree

10. If telemedicine had not been available for your consult today, which of the following would have been your alternative plan of action?

I would have driven to see the specialist face-to-face

I would have contacted my local clinical to see if they could assist

I wouldn't go see any doctor

The use of alternative medicine (honey - nigella - Indian installment, etc.)

Other .......

11. If telemedicine had not been available for your consult today, how far would you have had to travel to receive care?

Less than 15 minutes

15 - 30 minutes

30 minutes - 1 hour

1-2 hours

More than 2 hours

Other (please specify)

12. *If telemedicine had not been available and you had to travel to meet face-to-face with the provider to 
receive care, which of the following would apply? (please check all that apply)

I would have lost time from work

My companions would have lost time from work

I would have paid for meals while I was away from home

I would have paid for a hotel to spend the night

Other expenses (please specify)

13. In the future, which would you prefer?

Telemedicine Consultation

Face-to-face Consultation

14. Would you be willing to participate in another telemedicine consultation?

Yes

No

Not sure

15. Do you have any suggestions for improving consultations?

Mention it.......

16. What are the cases or diseases that are not suitable for telemedicine?

Mention it.......

17. Do you think the presence of the camera and other equipment can embarrass you or make you feel uncomfortable?

Agree

I don't agree

\section{Additional Information}

\section{Disclosures}

Human subjects: Consent was obtained or waived by all participants in this study. ISNC Research and Ethics Committee issued approval IEC Ref No.: H-24-19102020. Animal subjects: All authors have confirmed that this study did not involve animal subjects or tissue. Conflicts of interest: In compliance with the ICMJE uniform disclosure form, all authors declare the following: Payment/services info: All authors have declared that no financial support was received from any organization for the submitted work. Financial relationships: All authors have declared that they have no financial relationships at present or within the previous three years with any organizations that might have an interest in the submitted work. Other relationships: All authors have declared that there are no other relationships or activities that could appear to have influenced the submitted work.

\section{References}

1. Zayapragassarazan Z, Kumar S: Awareness, knowledge, attitude and skills of telemedicine among health professional faculty working in teaching hospitals. J Clin Diagn Res. 2016, 10:1-4. 10.7860/JCDR/2016/19080.7431

2. Report of the WHO group consultation on health telematics: a health telematics policy in support of WHO's health for all strategy for global health development. (1997). Accessed: February 12, 2021: https://apps.who.int/iris/handle/10665/63857.

3. Clemensen J, Rothmann MJ, Smith AC, Caffery LJ, Danbjorg DB: Participatory design methods in telemedicine research. J Telemed Telecare. 2017, 23:780-5. 10.1177/1357633x16686747

4. Polinski JM, Barker T, Gagliano N, Sussman A, Brennan TA, Shrank WH: Patients' satisfaction with and preference for telehealth visits. J Gen Intern Med. 2016, 31:269-75. 10.1007/s11606-015-3489-X 
5. Downes MJ, Mervin MC, Byrnes JM, Scuffham PA: Telephone consultations for general practice: a systematic review. Syst Rev. 2017, 6:128. 10.1186/s13643-017-0529-0

6. Wechsler LR, Tsao JW, Levine SR, et al.: Teleneurology applications: report of the Telemedicine Work Group of the American Academy of Neurology. Neurology. 2013, 12:670-6. 10.1212/WNL.0b013e3182823361

7. CDC: using telehealth to expand access to essential health services during the COVID-19 pandemic . (2020). Accessed: February 12, 2021: https://www.cdc.gov/coronavirus/2019-ncov/hcp/telehealth.html.

8. Calton B, Abedini N, Fratkin M: Telemedicine in the time of coronavirus. J Pain Symptom Manage. 2020, 60:12-4. 10.1016/j.jpainsymman.2020.03.019

9. Latifi R, Doarn CR: Perspective on COVID- 19: finally, telemedicine at center stage . Telemed J E Health. 2020, 26:1106-1109. 10.1089/tmj.2020.0132

10. Liu S, Yang L, Zhang C, Xiang YT, Liu Z, Hu S, Zhang B: Online mental health services in China during the COVID-19 outbreak. Lancet Psychiatry. 2020, 7:17-18. 10.1016/S2215-0366(20)30077-8

11. Vidal-Alaball J, Acosta-Roja R, Pastor Hernandez N, et al.: Telemedicine in the face of the COVID-19 pandemic. Aten Primaria. 2020, 52:418-22. 10.1016\%2Fj.aprim.2020.04.003

12. Hong YR, Lawrence J, Williams D Jr, Mainous A III: Population-level interest and telehealth capacity of US hospitals in response to COVID- 19: cross-sectional analysis of Google search and National Hospital Survey Data. JMIR Public Health Surveill. 2020, 7:18961. 10.2196/18961

13. Telemedicine regulations in the Kingdom of Saudi Arabia . (2018). Accessed: February 15, 2021 : https://nhic.gov.sa/en/Initiatives/Documents/Saudi\%20Arabia\%20Telemedicine\%20Policy.pdf.

14. Alhumud A, Al Adel F, Alwazae M, Althaqib G, Almutairi A: Patient satisfaction toward a tele-retinal screening program in endocrinology clinics at a tertiary hospital in Riyadh, Saudi Arabia. Cureus. 2020, 12:7986. 10.7759/cureus.7986

15. Sample size calculator. (2020). Accessed: February 15, 2021: https://www.calculator.net/sample-sizecalculator.html.

16. World Medical Association Declaration of Helsinki: ethical principles for medical research involving human subjects. (2008). Accessed: January 01, 2021: https://www.wma.net/policies-post/wma-declaration-ofhelsinki-ethical-principles-for-medical-research-inv.....

17. Institute of Medicine (US) Committee on the Health Professions Education Summit: Health Professions Education: A Bridge to Quality. Greiner AC, Knebel E (ed): National Academies Press (US), Washington; 2003.

18. Ramaswamy A, Yu M, Drangsholt S, Ng E, Culligan PJ, Schlegel PN, Hu JC: Patient satisfaction with telemedicine during the COVID-19 pandemic: retrospective cohort study. J Med Internet Res. 2020, 22:20786. 10.2196/20786

19. Fisk M, Livingstone A, Pit SW: Telehealth in the context of COVID-19: changing perspectives in Australia, the United Kingdom, and the United States. J Med Internet Res. 2020, $22: e 19264$. 10.2196/19264

20. Hassounah M, Raheel H, Alhefzi M: Digital response during the COVID-19 pandemic in Saudi Arabia . J Med Internet Res. 2020, $22: \mathrm{e} 19338.10 .2196 / 19338$

21. El-Mahalli AA, El-Khaf SH, Al-Qahtani MF: Successes and challenges in the implementation and application of telemedicine in the eastern province of Saudi Arabia. Perspect Health Inf Manag. 2012, 9:127.

22. Nesbitt TS, Marcin JP, Daschbach MM, Cole SL: Perceptions of local health care quality in 7 rural communities with telemedicine. J Rural Health. 2005, 21:79-85. 10.1111/j.1748-0361.2005.tb00066.x

23. Uscher-Pines L, Mehrotra A: Analysis of Teladoc use seems to indicate expanded access to care for patients . Health Aff (Millwood). 2014, 33:258-64. 10.1377/hlthaff.2013.0989

24. Al-Sofiani ME, Alyusuf EY, Alharthi S, Alguwaihes AM, Al-Khalifah R, Alfadda A: Rapid implementation of a diabetes telemedicine clinic during the Coronavirus disease 2019 outbreak: our protocol, experience, and satisfaction reports in Saudi Arabia. J Diabetes Sci Technol. 2019, 1:10-20. 10.1177/1932296820947094

25. Monaghesh E, Hajizadeh A: The role of telehealth during COVID-19 outbreak: a systematic review based on current evidence. BMC Public Health. 2020, 20:1193. 10.1186/s12889-020-09301-4

26. From isolation to coordination: how can telemedicine help combat the COVID-19 outbreak? . (2020). Accessed: February 15, 2021: https://www.medrxiv.org/content/10.1101/2020.02.20.20025957v1.articlemetrics.

27. Greenhalgh T, Wherton J, Shaw S, Morrison C: Video consultations for Covid-19. Br Med J. 2020, 368:m998. 10.1136/bmj.m998

28. Simcock R, Thomas TV, Estes C, Filippi AR, Katz MA, Pereira IJ, Saeed H: COVID- 19: global radiation Oncology's targeted response for pandemic preparedness. Clin Transl Radiat Oncol. 2020, 24:55-68. 10.1016/j.ctro.2020.03.009

29. Reeves JJ, Hollandsworth HM, Torriani FJ, et al.: Rapid response to COVID-19: health informatics support for outbreak management in an academic health system. J Am Med Inform Assoc. 2020, 27:853-9. 10.1093/jamia/ocaa037 